\title{
CÉLULAS SOLARES SENSIBILIZADAS POR PONTOS QUÂNTICOS
}

\author{
Ana Beatriz Ferreira Vitoretia ${ }^{a}$ Letícia Bernardes Corrêa ${ }^{a}$, Ellen Raphael ${ }^{a}$, Antonio Otavio T. Patrocinio ${ }^{\mathrm{b}}$, Ana Flávia \\ Nogueira $^{\mathrm{c}}$ e Marco Antônio Schiavon ${ }^{\mathrm{a}, *}$ \\ aDepartamento de Ciências Naturais, Universidade Federal de São João del-Rei, Campus Dom Bosco, 36301-160 São João del- \\ Rei - MG, Brasil

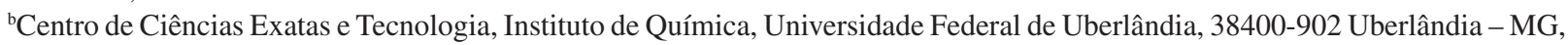 \\ Brasil \\ 'Instituto de Química, Universidade Estadual de Campinas, 13084-970 Campinas - SP, Brasil
}

Recebido em 03/08/2016; aceito em 03/11/2016; publicado na web em 25/11/2016

\begin{abstract}
QUANTUM DOT-SENSITIZED SOLAR CELLS. Quantum dot solar cells (QDSC) have been subject of extensive research in recent years. QDSC, as a promising alternative to existing solar cells, are among the candidates for next-generation photovoltaic devices that require low cost, high efficiency, so that quantum dots stand out for their unique features and versatile desirable on photovoltaic systems. The rapid development of QDSC provided a significant increase in energy conversion efficiency, which was certified for the first time in 2010 as $2 \%$ then being currently as $11.3 \%$, according to the National Renewable Energy Laboratory (NREL). This paper presents a review of the quantum dot-sensitized solar cells and the major advances reported concerning these cells, besides other types of cell architectures involving quantum dots.
\end{abstract}

Keywords: quantum dots; solar cells; quantum dot-sensitized solar cell.

\section{INTRODUÇÃO}

Nos dias atuais, há um forte apelo a respeito do aquecimento global proveniente do aumento da emissão de gases que agravam o efeito estufa, como o $\mathrm{CO}_{2}$, e suas várias consequências para o nosso planeta, como elevação do nível dos mares e alterações climáticas. ${ }^{1}$ Além disso, sabe-se que as reservas de combustíveis fósseis são finitas, e que a exploração destes combustíveis causa sérios danos ao meio ambiente, pois geram bilhões de toneladas de gases como $\mathrm{CO}_{2}$, $\mathrm{CO}, \mathrm{SO}_{2}, \mathrm{NO}_{\mathrm{x}}$, além de aerossóis que são lançados na atmosfera.

Nesse sentido, com o intuito de prevenir um colapso climático, ${ }^{2}$ países desenvolvidos têm agora por lei que diminuir drasticamente a emissão de tais gases, e, para isso, têm se valido de alternativas limpas e renováveis como biomassa, energia eólica e energia solar, 3,4 as quais vêm se destacando pela abundância das fontes e potencial o que permite sua aplicação de maneira eficiente.

A produção de energia por meio de células solares é uma alternativa para levar energia a diversas regiões do país, e, assim, estudos vêm sendo realizados e tecnologias têm sido amplamente testadas para produzir dispositivos fotovoltaicos que são aplicados na conversão da luz solar em eletricidade com mais eficiência. Dentre os materiais possíveis para aplicação em células solares, os pontos quânticos (PQs) têm atraído muito interesse em função, principalmente, de suas propriedades ópticas dependentes do tamanho das nanopartículas. ${ }^{5}$

Os pontos quânticos de semicondutores são constituídos de partículas nanocristalinas e apresentam diâmetro variando entre 1 e $10 \mathrm{~nm}$, o que corresponde a, aproximadamente, entre 100 e 1000 átomos por nanopartícula. Atualmente, a sua aplicação em dispositivos fotovoltaicos têm se tornado objeto de estudo de vários grupos de pesquisa no mundo, uma vez que células solares sensibilizadas com esses materiais atingiram $11,3 \%$ de rendimento de conversão solar, em 2016, de acordo com o Laboratório Nacional de Energias Alternativas - NREL dos Estados Unidos. ${ }^{6}$

Nos últimos anos, viram-se avanços conceituais e tecnológicos

*e-mail: schiavon@ufsj.edu.br rápidos em vários aspectos de células solares à base de pontos quânticos, e diversas oportunidades que os pontos quânticos podem oferecer. Além disso, prevê-se um amplo espaço para o desenvolvimento e avanços nesta área. Nos últimos anos, somente células solares de perovsquitas e de pontos quânticos atingiram aumentos percentuais na eficiência absoluta maiores que $1 \%$ ao ano. ${ }^{7}$

\section{O dispositivo fotovoltaico}

O efeito fotovoltaico pode ser entendido como sendo o fenômeno resultante da incidência de luz sobre a superfície do material semicondutor criando portadores de carga (pares elétrons-buracos), produzindo corrente elétrica. As células solares convertem a luz solar em corrente elétrica usando o efeito fotovoltaico. A primeira célula solar, criada em 1883 por Charles Fritts, atingiu 1\% de eficiência. Tal célula consistiu do revestimento de um semicondutor de selênio com uma camada muito fina de ouro, formando-se assim as junções. ${ }^{8}$

Células solares são comumente classificadas como de primeira, segunda e terceira geração. Células de junção $p-n$ de silício monocristalino ou multicristalino são os conversores fotovoltaicos mais comuns e que obtém as mais altas eficiências de conversão de energia. Porém, as várias etapas de processamento e a necessidade de elevada pureza dos cristais de silício elevam o custo energético de cada watt produzido. Já as células de segunda geração são baseadas em filmes finos inorgânicos, que são depositados em um substrato condutor. Essas células necessitam de baixa energia de produção e tem custos menores do que as células de primeira geração. Uma vez que é difícil preparar os filmes sem defeitos, a conversão de energia é menor. As células de segunda geração mais eficientes são as de GaAs, InP, GaInP, CIGS $\left(\mathrm{Cu}(\mathrm{In}, \mathrm{Ga})(\mathrm{Se}, \mathrm{S})_{2}\right)$, CdTe e CZTS $\left(\mathrm{Cu},(\mathrm{Zn}, \mathrm{Sn})(\mathrm{S}, \mathrm{Se})_{2}\right){ }^{7}$

Cálculos teóricos sobre a conversão máxima de energia obtida a partir da radiação solar mostram que o limite termodinâmico para a eficiência de conversão de energia luminosa em eletricidade de uma célula $p$ - $n$ de junção única é cerca de 32,9\%. ${ }^{9}$ Esse limite, conhecido como limite de Shockley e Queisser, ${ }^{10}$ origina do fato de que os fótons com energias abaixo do bandgap (energia de banda proibida) não são 
absorvidos, enquanto que fótons com energias acima do bandgap têm parte desta energia dissipada, principalmente na forma de calor. Todos os sistemas fotovoltaicos que podem, potencialmente, gerar eficiências de conversão de energia para além do limite de Shockley e Queisser são denominados como de terceira geração. ${ }^{11}$ Entretanto, segundo Ely e Swart, ${ }^{12}$ a definição de célula solar de terceira geração pode ser ambígua na questão de quais tecnologias são englobadas. Porém, há uma definição útil, em que as células que permitem uma utilização mais eficiente da luz solar do que as células baseadas em um único bandgap, são consideradas de terceira geração. Dentre elas estão as células orgânicas, de pontos quânticos, células tandem/ multijunções, células com portadores quentes (hot carriers), células sensibilizadas por corantes e células que fazem uso de tecnologias de upconversion e downconversion. ${ }^{12}$ Além dos mencionados anteriormente, o uso de conceitos avançados de células fotovoltaicas, tais como geração de múltiplos portadores de cargas e uso de impurezas, são as grandes bases para esses sistemas fotovoltaicos. ${ }^{2}$ As células solares híbridas, poliméricas e, recentemente, as de perovsquitas são também referidas como sistemas fotovoltaicos de terceira geração. $711,13,14$

Nesses dispositivos, busca-se uma alta eficiência quântica de conversão, o que significa que eles devem ser radiativamente eficientes. Múltiplos geradores/transportadores de carga excitônicas referem-se à formação de múltiplos éxcitons (pares elétron-buraco) por fóton absorvido, o que pode acontecer quando a energia do fóton absorvido é muito maior do que o gap do semicondutor. Este fenômeno também ocorre em semicondutores de corpo massivo, porém com baixa eficiência, pois o excesso de energia se dissipa afastando o calor antes que possa causar a formação de pares de elétrons-buracos adicionais de maneira eficaz. Em semicondutores de pontos quânticos, a taxa de dissipação de energia é significativamente reduzida, e eles estão confinados dentro de um volume extremamente reduzido, aumentando assim as suas interações e aumentando a probabilidade de formação de múltiplos éxcitons. ${ }^{11}$

Células solares sensibilizadas por corantes (DSSC, do inglês Dye-Sensitized Solar Cell) foram descritas em 1991 por Grätzel e O'Reagan, que mostraram que um substrato de $\mathrm{TiO}_{2}$ nanoestruturado e sensibilizado por um corante absorvia 780 vezes mais luz que um substrato plano, ${ }^{15}$ uma vez que a diminuição das dimensões do material garante um aumento na relação área superficial/volume, favorecendo uma maior adsorção do agente sensibilizador. ${ }^{16}$ Grätzel e O'Reagan desenvolveram um dispositivo constituído por um filme nanométrico transparente de óxido de titânio, depositado sobre um vidro condutor e recoberto por uma monocamada de um complexo de rutênio(II). Utilizaram uma solução de $\mathrm{I}^{-} / \mathrm{I}_{3}$ como eletrólito $\mathrm{O}$ contraeletrodo era um filme de platina depositado em um substrato condutor. Este conceito de célula ficou comumente conhecida como célula de Grätzel, pela utilização de moléculas de corante orgânico como absorvedor de luz em um filme mesoporoso de $\mathrm{TiO}_{2}$, propiciando o seu aprimoramento a partir de diversas classes de corantes, como complexos inorgânicos a base de rutênio, ${ }^{17,18}$ corantes naturais, ${ }^{19-21}$ bem como diferentes aspectos, como utilização de eletrólitos poliméricos. ${ }^{22,23}$ Estes dispositivos apresentaram considerável estabilidade, baixo custo e a eficiência de conversão certificada é de $11,9 \%,{ }^{6}$ no entanto, há relato de $13 \%$ de eficiência de conversão de energia, ${ }^{24}$ que ainda não foi certificada pelo NREL, órgão certificador. Os corantes utilizados como sensibilizadores necessitam ter o espectro de absorção que cubra boa parte da região do visível, a banda de condução mais elevada do que a banda de condução do semicondutor, grupos de ancoragem $\left(-\mathrm{COOH},-\mathrm{H}_{2} \mathrm{PO}_{3},-\mathrm{SO}_{3} \mathrm{H}\right.$, etc.) para ligar fortemente o corante à superfície do semicondutor, estabilidade térmica e ainda serem fotoestáveis. Os complexos metálicos e à base de rutênio (II) têm sido intensivamente investigados para aplicação em DSSC devido ao seu amplo espectro de absorção e às propriedades fotovoltaicas favoráveis. De modo geral, os complexos metálicos fotossensibilizadores consistem de um íon metálico central com ligantes auxiliares que possuem pelo menos um grupo de ancoragem. $\mathrm{O}$ íon metálico central é responsável pela absorção da luz na região do visível do espectro solar, e, por conseguinte, é importante pelas propriedades globais dos complexos. Os grupos de ancoragem são utilizados para ligar o corante com o semicondutor e facilitar a injeção de elétrons excitados para a banda de condução do semicondutor. Pode-se modificar qualquer parte do complexo para combinar os níveis de energia e assim otimizar a injeção de elétrons e melhorar a cinética de regeneração do corante..$^{18}$

\section{Pontos quânticos de semicondutores}

O semicondutor é o principal elemento em uma célula solar, pois é justamente ele quem absorve a radiação solar. Um semicondutor apresenta energia de banda proibida (bandgap) entre $0,8 \mathrm{eV}$ e $3,0 \mathrm{eV}$ e é definido como material sólido cristalino, de condutividade elétrica e largura de banda proibida intermediária aos materiais condutores (energia de banda proibida inferior a $0,5 \mathrm{eV}$ ) e isolantes (energia de banda proibida de aproximadamente $5 \mathrm{eV}$ ). Os semicondutores podem se dividir em intrínsecos (material puro, existente no estado natural) e extrínseco, em que a condutividade está atrelada à presença de impurezas devido aos processos de dopagem, de modo com que esses materiais sejam classificados em tipo $p$ ou tipo $n$. No primeiro, ocorre uma inserção na estrutura cristalina de átomos com deficiência em elétrons, ao passo que no semicondutor tipo $n$ ocorre a inserção de materiais com excesso de elétrons.

Dentre todos os semicondutores possíveis de serem empregados nas células solares, os pontos quânticos de semicondutores vêm obtendo destaque devido principalmente às suas propriedades ópticas dependentes do tamanho das nanopartículas. ${ }^{2,5}$

Por definição, pontos quânticos (PQs) são materiais semicondutores nanocristalinos de diâmetro variando entre 1 e $10 \mathrm{~nm}$ e podem ser divididos de acordo com os diferentes grupos da Tabela Periódica que seus elementos constituintes pertencem, como: IV-VI (sulfeto de chumbo, $\mathrm{PbS}$ ), II-VI (telureto de cádmio, CdTe) e III-V (fosforeto de gálio, GaP). Os pontos quânticos apresentam o efeito de confinamento quântico, o que os caracterizam como materiais intermediários entre átomos, moléculas e um corpo massivo, como representado na Figura 1a. De acordo com a teoria dos orbitais moleculares, $n$ orbitais atômicos geram $n$ orbitais moleculares, e, assim, em um corpo massivo, o valor de $n$ é tão grande que ocorre a aproximação dos níveis de energia, tornando-os um quasi-contínuo. ${ }^{25,26}$ Entretanto, para os PQs, o que se observa são níveis discretos de energia e energia de banda proibida maior, o que é justificado pelo número reduzido de átomos e moléculas contidas nesse material. ${ }^{26}$

Os PQs são considerados materiais zero dimensional e por isso apresentam propriedades ópticas fortemente dependentes do tamanho do nanocristal. Isso se deve ao efeito do confinamento quântico justificado pelo surgimento de níveis discretos de energia nas bandas de valência e condução do material. ${ }^{27}$ De acordo com a Figura 1b, é possível perceber a relação entre tamanho e luminescência nesses semicondutores, visto que quando ocorre um aumento no tamanho da partícula a luminescência do material se desloca para comprimentos de onda maiores do espectro eletromagnético. ${ }^{28}$

Os PQs apresentam diversas propriedades que os diferenciam de outros semicondutores, entre as quais merecem destaque: fotoluminescência dependente do tamanho, ampla absorção de luz, alta intensidade de luminescência e boa estabilidade química. ${ }^{29}$ Os pontos quânticos de semicondutores podem ser divididos em diferentes grupos da tabela periódica, tais como II-IV, III-V, IV-VI e I-III-VI ${ }_{2}{ }^{5}$ 


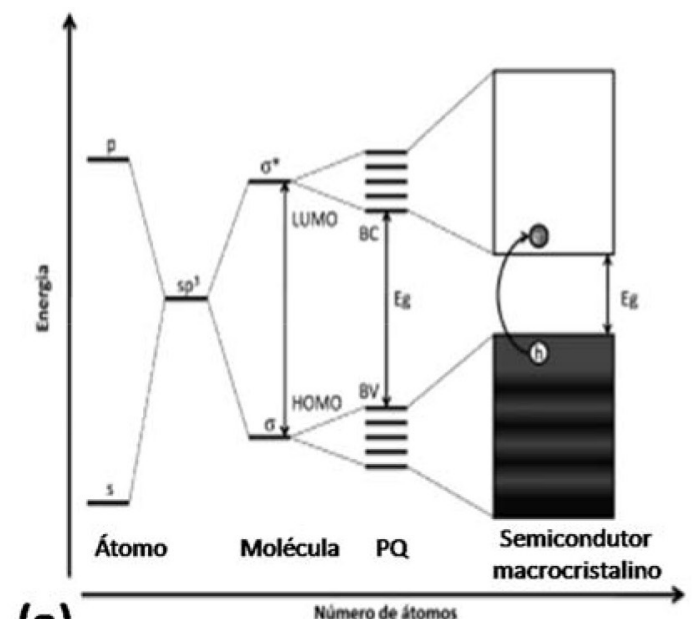

(a)
Número de stomos

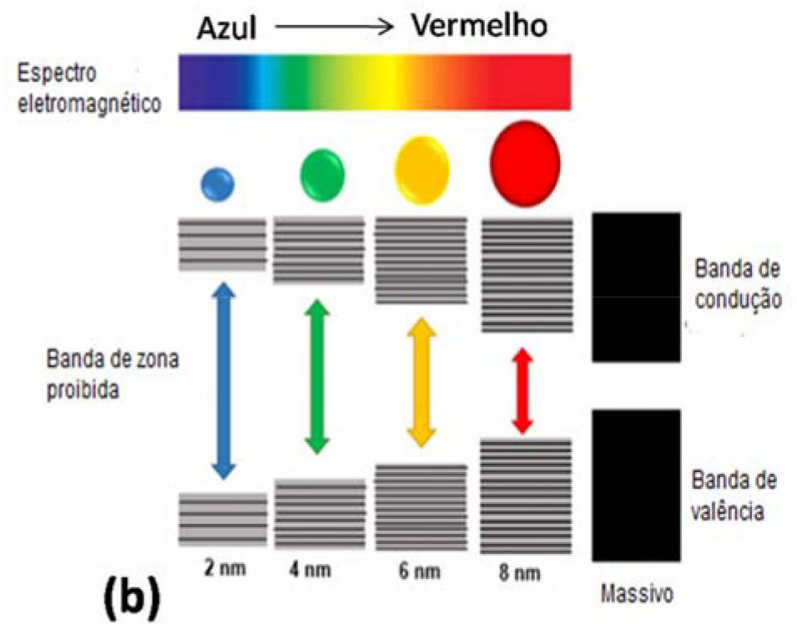

Figura 1. (a) Níveis eletrônicos presentes em átomos, moléculas, corpos massivos e em pontos quânticos. Adaptado da ref. 26e (b) Variação da luminescência e da energia de banda proibida de acordo com os tamanhos dos nanocristais. Adaptado da ref. 27

A Figura 2 apresenta os principais PQs e os respectivos valores de bandgap dos seus bulks. ${ }^{30-33}$

Na década de 80 , foram sintetizados os primeiros PQs da história, utilizando-se de precursores metálicos e calcogenetos. Entretanto, tal rota não produziu uma boa densidade de nanocristais e também não apresentou um efetivo controle de tamanho dos mesmos. ${ }^{35}$

Na década de 90, a equipe de Murray conseguiu obter nanocristais coloidais, utilizando precursores organometálicos em um solvente coordenante em temperaturas da ordem de $300{ }^{\circ} \mathrm{C} .{ }^{36}$ Ainda na década de 90 , foram obtidos PQs dispersos em água, os quais foram primeiramente descritos por Rogach e seus colaboradores. ${ }^{37}$ Tal rota é de baixo custo, apresenta boa reprodutibilidade, baixa toxicidade, porém gera pontos quânticos com valores de rendimento quântico menores, variando de 38 a $67 \%,{ }^{38}$ quando comparados com aqueles obtidos via rota organometálica. Assim, uma estratégia para se aumentar a eficiência dos PQs sintetizados via rota aquosa é o crescimento de uma camada externa (matriz inorgânica) sobre os nanocristais, formando então o sistema core/shell.

O sistema caroço/casca (core/shell) utiliza dois semicondutores: o core (caroço) que fica no centro e é recoberto pelo outro semicondutor shell (casca). Tais sistemas são classificados em tipo I ou II. No tipo I, o semicondutor de maior zona proibida encontra-se na casca, já no caroço está presente o semicondutor de menor zona proibida. Aqui, os buracos e elétrons aparecem localizados no caroço, de modo que

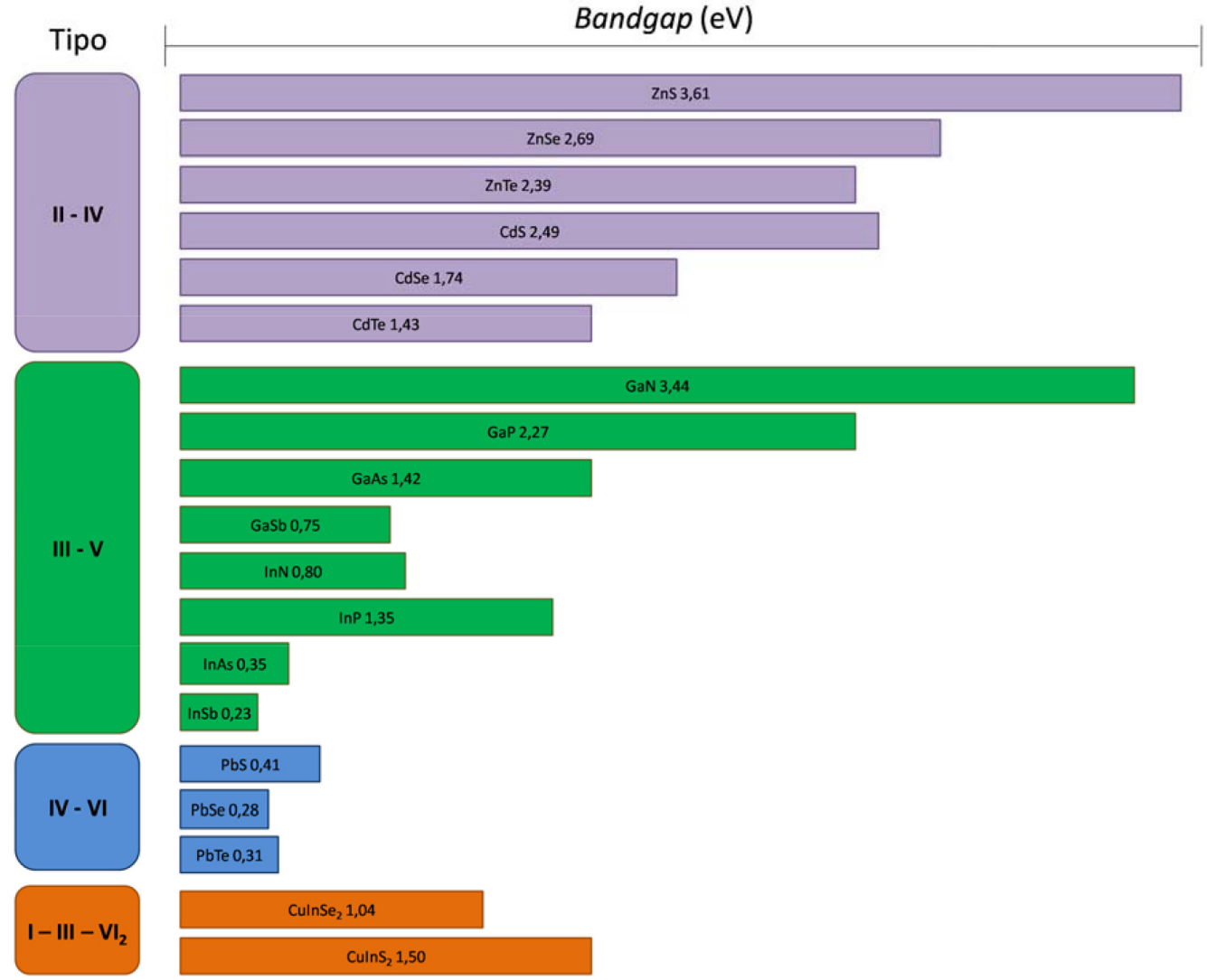

Figura 2. Principais pontos quânticos divididos em grupos da tabela periódica e os valores de bandgap dos seus bulks. Baseada na ref. 34 
o material apresenta maior rendimento quântico, devido à menor probabilidade de perda por decaimentos não radioativos. No tipo II, os elétrons ficam alojados na região da casca, e os buracos na região do caroço, apresentando assim uma melhor separação dos portadores de carga. ${ }^{4,38}$ Uma revisão sobre o desenvolvimento dos principais métodos de síntese de PQs coloidais de semicondutores já foi publicada pelo nosso grupo de pesquisa. ${ }^{5} \mathrm{Um}$ importante aspecto da síntese de PQs coloidais é a presença de moléculas que atuam como ligantes de superfície, cuja função é evitar agregação, dar estabilidade, possibilidade de controle do tamanho e da morfologia dos PQs, além de possibilitar funcionalizações. ${ }^{39}$ As características dos ligantes de superfície são de fundamental importância para a sua utilização em sistemas fotoeletroquímicos, como será apresentando adiante.

\section{CÉLULAS SOLARES SENSIBILIZADAS POR PONTOS QUÂNTICOS}

A utilização de PQs em células solares foi inicialmente desenvolvida a partir das células sensibilizadas por corantes, pela simples substituição dos corantes usados por Grätzel por PQs. Pontos quânticos vêm sendo utilizados em dispositivos fotovoltaicos, com a finalidade de aumentar a eficiência de conversão de energia solar em eletricidade e também por apresentarem outras vantagens como: confinamento quântico, estabilidade e energia de zona proibida que variam de acordo com o tamanho da nanopartícula e emissão de múltiplos fótons.

O primeiro sistema fotoeletroquímico usando pontos quânticos foi publicado pela equipe de Weller em 1990, que utilizavam pontos quânticos de CdS depositados in situ em um substrato de $\mathrm{TiO}_{2}$ nanoestruturado, obtendo um valor de eficiência de fotoconversão eletroquímica de aproximadamente $6 \%{ }^{40,41}$ Entretanto, como os valores foram relativamente mais baixos que aqueles obtidos quando corantes moleculares eram usados como sensibilizadores do $\mathrm{TiO}_{2}$, não houve interesse na utilização desses materiais. Somente em 1998 com a utilização de PQs coloidais é que se demonstrou o potencial dessas nanopartículas na geração de fotocorrente, como será apresentado adiante.

As células solares sensibilizadas por pontos quânticos (QDSSC, do inglês Quantum Dot-Sensitized Solar Cells) podem ser esquematizadas como a apresentada na Figura 3. É possível observar que elas operam de modo semelhante a uma célula DSSC. Assim, são constituídas por um fotoanodo, feito de vidro condutor transparente, uma camada de semicondutor, em que geralmente se utiliza o $\mathrm{TiO}_{2}$ e também uma camada de PQ adsorvido a este semicondutor, além de um eletrólito redox e um contraeletrodo depositado sobre um vidro condutor. ${ }^{42,43}$ Para que o dispositivo funcione, inicialmente

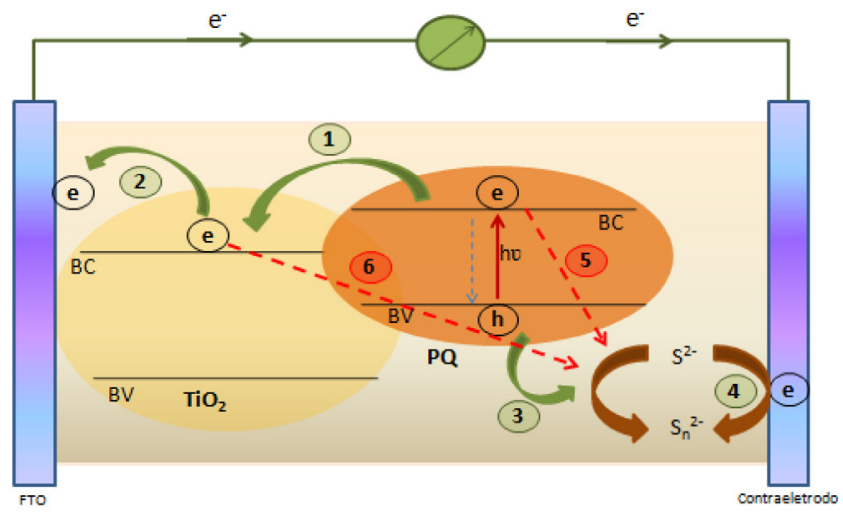

Figura 3. Esquema de uma célula solar sensibilizada por pontos quânticos com os processos de transferência de cargas envolvidos. Baseada na ref. 45 é necessário que o ponto quântico absorva a radiação solar, e que o elétron da banda de condução do ponto quântico seja transferido para a banda de condução do $\mathrm{TiO}_{2}$, seguindo então para o substrato de vidro condutor e, então, gerar corrente elétrica no circuito. ${ }^{44} \mathrm{De}$ modo análogo às DSSC, o buraco formado nos PQs será regenerado por reações redox do eletrólito, que por sua vez dependerá do contraeletrodo para se regenerar, Figura 3.

Um dos fatores primordiais para o sucesso operacional das células solares sensibilizadas por pontos quânticos é o eficiente transporte dos portadores de carga em direção aos eletrodos. ${ }^{46} \mathrm{O}$ transporte, bem como a separação de cargas nesse dispositivo, ocorre na interface entre o semicondutor e o eletrólito. ${ }^{43}$

Poucos eletrólitos diferentes têm sido propostos para células solares sensibilizadas por pontos quânticos. O eletrólito polissulfeto $\left(\mathrm{S}^{2-} / \mathrm{S}_{\mathrm{n}}{ }^{2-}\right)$ à base de sulfeto de sódio e enxofre é o mais utilizado. Geralmente quando esse par redox é empregado, a concentração das espécies oxidadas é sempre menor do que a concentração das espécies reduzidas, a fim de evitar recombinação com elétrons no óxido. Aproveitando a vantagem vinda das células solares sensibilizadas por corantes nas últimas décadas e considerando as semelhanças entre as células solares sensibilizadas por corantes e por pontos quânticos, eletrólitos orgânicos contendo o $\mathrm{I}_{3}^{-} / \mathrm{I}^{-}$como par redox também foram testados em QDSSC. ${ }^{47}$ Esses eletrólitos deram os melhores resultados para DSSC. No entanto, a maioria dos pontos quânticos sofrem de fotodegradação quando usado em combinação com este par redox, a menos que sejam protegidos com um revestimento de $\mathrm{TiO}_{2}$.

Em relação ao contraeletrodo, a platina é o de uso mais generalizado em DSSC, porque eles apresentam baixa resistência de transferência de carga para o eletrólito $\mathrm{I}_{3}-/ \mathrm{I}^{-}$. No entanto, em contato com eletrólito polissulfeto aquoso, os contraeletrodos de platina ficam "envenenados". Assim, contraeletrodos de materiais alternativos, tais como ouro, ${ }^{48}$ carbono, ${ }^{49}$ e sulfetos metálicos como $\mathrm{Cu}_{2} \mathrm{~S},{ }^{48,50}$ têm sido empregados. As melhores eficiências relatadas até agora têm sido obtidas para QDSSCs utilizando polissulfeto que empregam $\mathrm{Cu}_{2} \mathrm{~S}$ em latão ou óxido de $\mathrm{Cu}_{2} \mathrm{~S}$ /grafeno como contraeletrodo. ${ }^{50,51}$

A Figura 3 ilustra também o processo simultâneo de transferência de cargas em células solares sensibilizadas por pontos quânticos (numeradas de 1 a 3 na Figura 3 ). ${ }^{35} \mathrm{O}$ processo ocorre da seguinte maneira: (1) Injeção de elétrons: ocorre do ponto quântico excitado para as nanopartículas do óxido metálico $\left(\mathrm{TiO}_{2}\right)$. É um processo muito rápido, ocorre com constantes de velocidade na ordem de picossegundos. ${ }^{52}$ Entretanto, o fator limitante da cinética de transferência de cargas global se dá pela etapa lenta de transferência de buracos; (2) Transferência de elétrons: ocorre das nanopartículas do semicondutor $\mathrm{TiO}_{2}$ para a superfície do eletrodo; (3) Transferência de buracos para o par redox: o par redox presente na estrutura desempenha um importante papel na regeneração do semicondutor; (4) Regeneração do par redox no contraeletrodo: para melhorar o desempenho das células solares sensibilizadas por pontos quânticos é necessário que ocorra uma rápida descarga de elétrons no contraeletrodo; (5) e (6) relacionam-se com a recombinação do par elétron-buraco, do PQ para o par redox e da interface do $\mathrm{TiO}_{2}$ para o par redox, respectivamente. ${ }^{45}$ Tais processos levam à desativação do fóton absorvido, diminuindo a eficiência de conversão da célula solar.

Dentre os pontos quânticos, alguns são mais utilizados em células solares sensibilizadas. A Tabela 1 lista os principais PQs sensibilizadores, o semicondutor utilizado, bem como referências. Atualmente existem muitos trabalhos com diferentes combinações de pontos quânticos, estruturas do tipo core/shell, entre outros. Há muito mais sistemas que os relatados aqui, porém a ideia é elucidar apenas quais são mais comumente utilizados neste tipo de célula solar.

Ainda são poucos os grupos de pesquisa no Brasil que têm trabalhos com células solares sensibilizadas por pontos quânticos, 
Tabela 1. Principais materiais utilizados em células solares sensibilizadas por pontos quânticos

\begin{tabular}{lcc}
\hline Semicondutor & $\begin{array}{c}\text { Ponto quântico } \\
\text { sensibilizador }\end{array}$ & Referências \\
\hline $\mathrm{TiO}_{2}$ & $\mathrm{CdS}$ & $53-56$ \\
$\mathrm{TiO}_{2}$ & $\mathrm{CdSe}$ & $57-61$ \\
$\mathrm{TiO}_{2}$ & $\mathrm{CdS} / \mathrm{CdSe}$ & $62-79$ \\
$\mathrm{TiO}_{2}$ & $\mathrm{CdTe} / \mathrm{CdS}$ & 76 \\
$\mathrm{TiO}_{2}$ & $\mathrm{CdTe} / \mathrm{CdSe}$ & 80 \\
$\mathrm{TiO}_{2}$ & $\mathrm{PbS}$ & $81-84$ \\
$\mathrm{TiO}_{2}$ & $\mathrm{PbS} / \mathrm{CdS}$ & 85 \\
$\mathrm{TiO}_{2}$ & $\mathrm{CuInS}$ & 86,87 \\
$\mathrm{TiO}_{2}$ & $\mathrm{CuInS} / \mathrm{CdS}$ & 88 \\
$\mathrm{TiO}_{2}$ & $\mathrm{CuInS} / \mathrm{CdSe}$ & 89 \\
$\mathrm{TiO}_{2}$ & $\mathrm{CuInSe}$ & 90 \\
$\mathrm{TiO}_{2}$ & $\mathrm{CuInSe} / \mathrm{ZnS}$ & 90 \\
$\mathrm{ZnO}_{\mathrm{ZnO}}$ & $\mathrm{CdS} / \mathrm{CdSe}$ & $91-94$ \\
$\mathrm{SnO}_{2}$ & $\mathrm{PbS} / \mathrm{CdS} / \mathrm{CdSe}$ & 95 \\
$\mathrm{SnO}_{2}$ & $\mathrm{CdS} / \mathrm{CdSe}$ & 96,97 \\
\hline
\end{tabular}

dentre os quais podemos citar o Grupo de Pesquisa em Química de Materiais (GPQM) da Universidade Federal de São João del-Rei (UFSJ), o Centro de Tecnologia da Informação Renato Archer (CTI), o Laboratório de Materiais Aplicados e Interfaces (LAMAI) da Universidade Federal do Rio Grande do Sul (UFRGS), o Núcleo de Tecnologia em Energia Solar (NT-Solar da PUCRS), o Centro de Tecnologia Estratégicas do Nordeste (CETENE) e o Laboratório de Nanotecnologia e Energia Solar (LNES) da Universidade Estadual de Campinas (UNICAMP).

Uma classe de material que vem ganhando destaque nas aplicações em células solares são as chamadas perovsquitas, definido como o grupo de compostos com uma estrutura cristalina que se assemelha à estrutura da perovskita mineral, cujo representante clássico é o titanato de cálcio $\left(\mathrm{CaTiO}_{3}\right) .{ }^{98} \mathrm{O}$ tipo de perovsquita mais utilizado em células solares são materiais semicondutores híbridos orgânicos-inorgânicos à base de haletos de chumbo, com fórmula geral $\mathrm{MPbX}_{3}$ $\left(\mathrm{M}=\mathrm{CH}_{3} \mathrm{NH}_{3}, \mathrm{X}=\mathrm{Cl}, \mathrm{Br}, \mathrm{I}\right)$, que além de baixo custo, apresentam um excelente desempenho quando utilizados como sensibilizadores em dispositivos fotovoltaicos de terceira geração, o que propiciou um rápido desenvolvimento destes dispositivos com um significativo aumento na eficiência de conversão de energia em um curto espaço de tempo, sendo reportada pela primeira vez em 2009 como 3,8\%, ${ }^{99}$ e atualmente já atingiu o valor de $22,1 \% .{ }^{6}$ No entanto, problemas de estabilidade ainda limitam a aplicação prática desses materiais. Com isso, $\mathrm{PQs}$ de perovsquitas à base de chumbo tri-halogeneto de césio $\left(\mathrm{CsPbX}_{3}\right)$, completamente inorgânico, têm sido estudados atualmente como uma alternativa para aplicação em células solares, ${ }^{100}$ uma vez que já foi reportada a montagem de um dispositivo fotovoltaico sensibilizado com PQs de perovsquitas híbridos pela primeira vez em 2011, obtendo-se eficiência de conversão de 6,5\%. ${ }^{101}$ Em 2016, PQs coloidais de perovsquitas inorgânicos foram aplicados como sensibilizadores, por Kulbak e colaboradores, ${ }^{102}$ obtendo $6,6 \%$ de eficiência de conversão de energia, apresentando maior estabilidade em relação às perovsquitas à base de metilamônio.

\section{PREPARAÇÃO DE CÉLULAS SOLARES SENSIBILIZADAS POR PONTOS QUÂNTICOS}

Os PQs utilizados como sensibilizadores nas células solares podem ser depositados basicamente por duas técnicas diferentes: in situ e ex situ. As duas técnicas são possíveis de serem empregadas para produção em larga escala.

Na técnica in situ utilizam-se basicamente os métodos SILAR (do inglês Successive Ionic Layer Adsorption and Reaction) ou deposição química. No primeiro, os precursores catiônicos e aniônicos são separados em dois ambientes diferentes. Posteriormente, o eletrodo coberto com o semicondutor $\mathrm{TiO}_{2}$ é imerso na solução que contém os precursores catiônicos e depois na solução contendo o precursor aniônico ou vice-versa. Após cada imersão realizada, procede-se a lavagem e secagem do eletrodo. Neste método, o controle do tamanho do filme se dá de acordo com o número de ciclos de imersão realizados. Na deposição química, prepara-se separadamente uma solução catiônica e outra aniônica que serão colocadas em um recipiente, de forma que o eletrodo quando imerso nessa solução irá reagir lentamente com os íons presentes nessa solução. ${ }^{42}$ Os dois métodos levam a uma conexão direta entre os PQs e a matriz do semicondutor, entretanto, não permitem um eficaz controle do tamanho das partículas e das propriedades ópticas do material.

A técnica ex situ surgiu com o intuito de aumentar a eficiência de conversão, utilizando do alinhamento das posições das bandas de valência e condução do semicondutor. ${ }^{41}$ Neste método, os pontos quânticos previamente sintetizados com ligantes de superfície podem ser depositados diretamente sobre o eletrodo, via adsorção direta por imersão ou gotejamento. Esse método permite o controle preciso dos tamanhos e, portanto, das propriedades de absorção espectral. ${ }^{48,103}$ No entanto, o uso dessa metodologia até então resultou apenas em uma baixa cobertura de superfície e a um elevado grau de agregação dos pontos quânticos. ${ }^{104}$

$\mathrm{O}$ uso de ligantes moleculares como agentes modificadores do eletrodo de óxido metálico também é uma metodologia para realizar a deposição dos pontos quânticos ex situ. Neste procedimento, o eletrodo de $\mathrm{TiO}_{2}$, por exemplo, é imerso em uma solução de um ligante molecular bifuncional, ligantes estes que normalmente apresentam um grupo carboxilato, que se liga ao óxido, e um grupo tiol, que permanece livre para se ligar ao ponto quântico. Após o eletrodo ser modificado com esse ligante, ele é imerso em uma solução de ponto quântico para adsorção. ${ }^{2}$ Outro método de deposição ex situ de pontos quânticos é por eletroforese. A deposição eletroforética realiza-se mediante a aplicação de um campo elétrico entre dois eletrodos imersos numa suspensão de PQs. O método permite um bom "empacotamento" das nanopartículas de PQs sobre o eletrodo puro ou na estrutura do óxido. A quantidade de PQs na superfície do eletrodo pode ser manipulada pela concentração ou tempo de deposição. ${ }^{28}$ A Figura 4 ilustra as diferentes técnicas possíveis de serem empregadas na deposição de pontos quânticos sobre substrato de um óxido metálico como o $\mathrm{TiO}_{2}$.

Dentre as células solares sensibilizadas por pontos quânticos algumas merecem destaque pelas eficiências alcanças e certificadas. Kamat e Santra conseguiram atingir a marca de 5,4\% de eficiência para uma célula de CdS dopada com íons $\mathrm{Mn}^{2+}$ feita por método SILAR sobre o $\mathrm{TiO}_{2}$ em 2012. ${ }^{51}$ Em 2013, Klimov e colaboradores construíram uma célula de CuInSeS e depositaram esse PQ sobre o $\mathrm{TiO}_{2}$ fazendo o uso de ligantes bifuncionais e deixando o substrato imerso na solução de PQ por $36 \mathrm{~h}$. Dessa maneira, eles obtiveram 5,5\% de eficiência para tal célula. ${ }^{105}$ Já em 2014, Bisquert e colaboradores conseguiram, pela passivação da superfície do $\mathrm{CuInS}_{2}$ com $\mathrm{ZnS}$, uma eficiência certificada de 6,7\%. ${ }^{106} \mathrm{Tal}$ eficiência é a melhor até o momento para células solares sensibilizadas por pontos quânticos e também demonstra a possibilidade da obtenção de um bom desempenho comparável ou até superior às QDSSC que utilizam metais tóxicos, tais como PQs de cádmio e chumbo. 


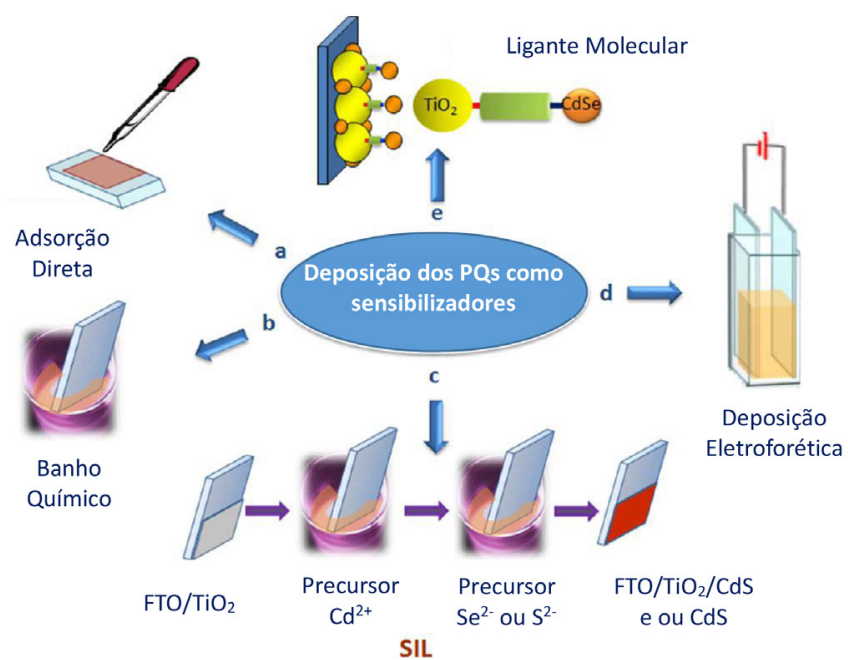

Figura 4. Ilustração esquemática de métodos para depositar uma suspensão $P Q$ na superfície do eletrodo. Estes métodos incluem: (a) adsorção direta, (b) deposição por banho químico, (c) SILAR, (d) deposição eletroforética, e (e) uma uso de ligante molecular bifuncional. Adaptada da ref 46

\section{PRINCIPAIS AVANÇOS DESCRITOS NA LITERATURA PARA CÉLULAS SOLARES DE PONTOS QUÂNTICOS}

Após o trabalho de Weller sobre a sensibilização de $\mathrm{TiO}_{2}$ com pontos quânticos de $\mathrm{CdS},{ }^{41}$ o primeiro estudo contendo a ideia de células solares sensibilizadas por pontos quânticos à base de fosfeto de índio (InP) coloidal foi descrito em 1998 por Nozik e colaboradores, no qual ficou evidenciado que os PQs coloidais ficam absorvidos na estrutura do $\mathrm{TiO}_{2}$ de maneira homogênea e que o processo de fotoindução ocorre quando os elétrons são deslocados entre as bandas de condução dos pontos quânticos e do $\mathrm{TiO}_{2} \cdot{ }^{107}$ Além disso, observaram que nanopartículas maiores absorviam melhor a luz e eram capazes de gerar maior fotocorrente, devido a menor quantidade de ligantes de superfície presente nessas nanopartículas. Assim, este trabalho é considerado o marco inicial da utilização de PQs na geração de fotocorrente para células solares.

As células solares sensibilizadas por pontos quânticos foram desenvolvidas utilizando os mesmos materiais empregados nos dispositivos convencionais e que já apresentavam resultados favoráveis. Entretanto, com o tempo, a arquitetura e alguns componentes foram modificados em busca de uma melhor adequação aos PQs visando aumentar sua eficiência.

A síntese de pontos quânticos caroço/casca (core/shell) é considerada uma estratégia para aumentar a eficiência destes materiais devido à eficiente separação de carga que o material passa a apresentar. A Figura 5 apresenta um diagrama de separação de cargas do tipo I e II das estruturas core/shell. Em I, a casca bloqueia a transferência de elétrons fotoexcitados, ao passo que em II atua como uma ponte para a transferência de elétrons.

Em 2009, Kuan-Ting-Kuo e sua equipe, ${ }^{108}$ ao estudarem a influência da espessura da casca nas estruturas core/shell, concluíram que a eficiência de conversão relaciona-se diretamente com o aumento da espessura, assim, quanto maior a eficiência maior a espessura, fato que pode ser observado até que defeitos comecem a existir na interface da estrutura core/shell.

Tal estratégia passou a ter ainda mais credibilidade em 2011, quando Shi e colaboradores, ${ }^{109}$ utilizando as estruturas core/shell do tipo II de CdTe/CdS com MPA (ácido 3-mercaptopropiônico) como ligante de superfície, observaram o crescimento da casca de CdS em torno do caroço CdTe e com isso uma melhora no rendimento quântico e na estabilidade dos cristais.
I

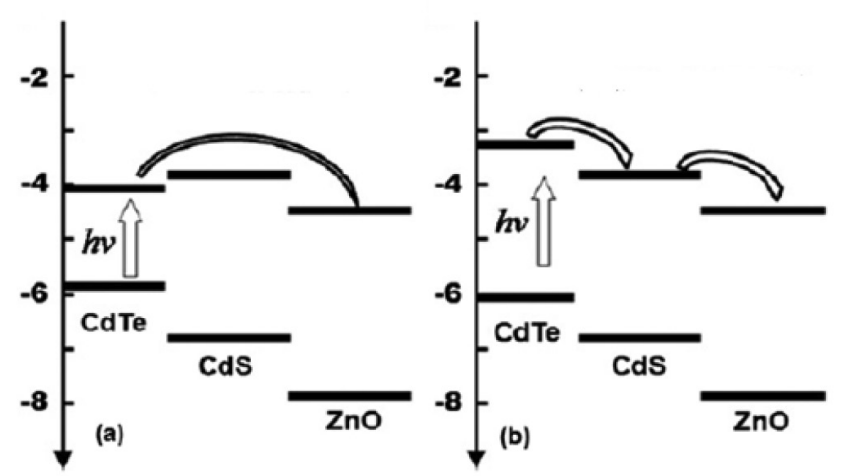

Figura 5. Diferenças na transferência de elétrons na estrutura caroço/casca (core/shell) dos tipos I e II. Adaptada da ref 2

Com o intuito de aumentar ainda mais a eficiência das células solares sensibilizadas por pontos quânticos, diversos estudos vêm sendo realizados em cada componente do dispositivo.

Com o avanço na preparação de nanotubos de carbono (NTC) surgiu a possibilidade da implementação desses materiais nas células solares sensibilizadas por pontos quânticos. A primeira vez que NTC foram utilizados como material sensibilizador data de 2005, quando Sheeney-Haj-Khia e colaboradores suportaram, em um eletrodo de ouro, nanotubos modificados com pontos quânticos de CdS. ${ }^{110} \mathrm{Um}$ esquema parecido foi desenvolvido por Kamat e colaboradores, ${ }^{111}$ que com o auxílio da técnica de eletroforese depositaram o material de NTC/CdSe em um substrato altamente condutivo. Na interação do estado excitado entre CdSe e NTC observou-se um aumento na transferência de elétrons. Assim, NTC/CdSe tem se apresentado como um material promissor para o desenvolvimento de dispositivos fotovoltaicos com valores favoráveis de eficiência.

Em 2008, Lee e sua equipe estudaram as integrações existentes entre os NTCs e o semicondutor $\mathrm{TiO}_{2}$ e que atuavam no sentido de direcionar as cargas até o eletrodo. ${ }^{12}$ Tomando como base esses resultados, em 2010, Chen e colaboradores desenvolveram uma célula solar sensibilizada por pontos quânticos, em que os NTCs eram posicionados verticalmente, seguidos de uma camada de nanofios de $\mathrm{ZnO}$ e a última camada de pontos quânticos de CdSe. Este dispositivo atingiu $1,46 \%$ de eficiência de conversão, o que coloca a integração entre NTCs e óxidos metálicos em um papel relevante para pesquisas futuras envolvendo as células solares sensibilizadas por pontos quânticos. ${ }^{113}$

Nesse mesmo ano, Kamat e colaboradores propuseram estratégias para ajudar no desenvolvimento de NTCs acoplados a semicondutores. ${ }^{46} \mathrm{O}$ primeiro dispositivo descrito então por Kamat baseava-se em clusters de fulereno atuando como material aceptor de elétrons conforme ilustrado na Figura 6. Esta Figura ilustra o processo de fotoindução que ocorre entre o ponto quântico de CdSe e o fulereno $\left(\mathrm{C}_{60}\right)$, seguido pelo transporte de elétrons através do cluster de fulereno que será coletado na superfície do eletrodo aceptor de elétrons. ${ }^{46}$

Por outro lado, o segundo dispositivo descrito por Kamat empregou NTCs como condutores de cargas. O uso de NTCs para suportar partículas de semicondutores têm sido uma alternativa para capturar cargas geradas e transportá-las até a superfície do eletrodo. ${ }^{46}$

Em um outro trabalho, Kamat fez uso de nanoestruturas de óxido de grafeno (OG) incorporadas nos filmes coloidais de pontos quânticos (CdSe). ${ }^{114} \mathrm{~A}$ incorporação desses OG melhorou a separação de carga e a condução dos elétrons através do filme de PQ, resultando em uma sensibilização 3-D. Tal arquitetura de célula aumentou em torno de $150 \%$ a resposta de fotocorrente em relação às células sem a incorporação do OG. O uso dessas nanoestruturas baseadas em 


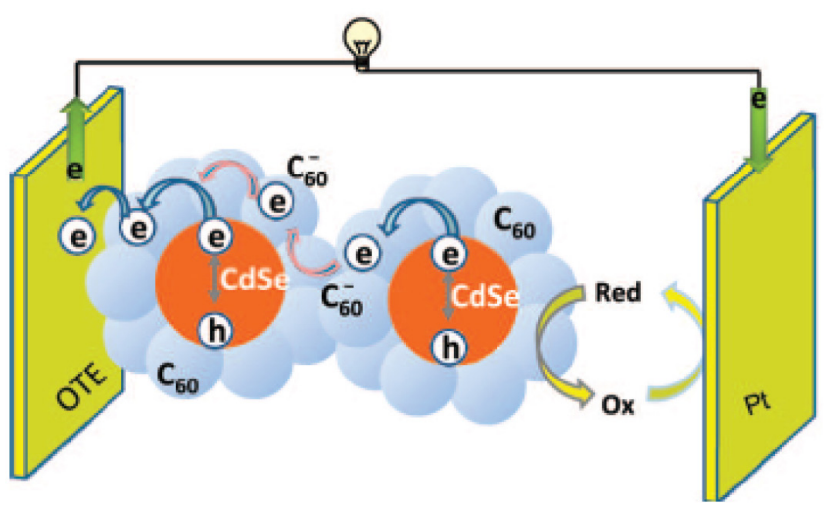

Figura 6. Aparato utilizado para geração de corrente por meio de CdSe e fulereno $^{46}$

grafeno pode possibilitar aumentos na eficiência de absorção de luz pelos fotoanodos com pontos quânticos. Desde que se alcance um alto grau de dispersão do grafeno dentro do filme de PQ, será possível aproveitar a espessura atômica, a grande área superficial e a condutividade do grafeno para estender a carga útil do PQ para terceira dimensão. Neste trabalho, a incorporação do grafeno nos filmes de PQs representou um passo apreciável para a superação de problemas de condutividade intrínsecas aos filmes de PQ, e como tal, abriu um novo caminho para a melhoria dos sensibilizadores e o desempenho das células solares sensibilizadas por pontos quânticos.

Os materiais semicondutores de óxidos metálicos de ampla energia de banda proibida têm sido utilizados com frequência nas células solares sensibilizadas por pontos quânticos. As diversas morfologias desses materiais estão sendo muito exploradas com o objetivo de alcançar um maior poder de eficiência de conversão. Assim, nanofios e nanotubos de óxidos metálicos são utilizados com o intuito de aumentar a condutividade dos filmes finos, aumentando assim a eficiência de transporte de cargas. O material semicondutor de elevada banda proibida comumente utilizado no dispositivo é o $\mathrm{TiO}_{2}$. Entretanto, outros substratos têm sido estudados com a finalidade de se obter maior diversidade e desempenho ainda melhor. Como por exemplo: $\mathrm{Nb}_{2} \mathrm{O}_{5}, \mathrm{SnO}_{2}, \mathrm{Al}_{2} \mathrm{O}_{3}$ e $\mathrm{ZnO}{ }^{115}$

$\mathrm{O} \mathrm{ZnO}$ tem sido visto como uma alternativa para aplicações em células solares, devido às vantagens que este material apresenta quando comparada com o filme de $\mathrm{TiO}_{2}$. Assim como o $\mathrm{TiO}_{2}$, o $\mathrm{ZnO}$ é um semicondutor do tipo $n$, com energia de zona proibida de $3,3 \mathrm{eV}$, mas que apresenta uma maior mobilidade de elétrons. Além disso, pode ser cristalizado com maior facilidade em diversas morfologias em arquitetura unidimensional e apresenta eficiência similar ao $\mathrm{TiO}_{2}{ }^{116}$

Sudhagar e colaboradores, ${ }^{117}$ em 2011, descreveram um estudo baseado na utilização de uma estrutura híbrida de $\mathrm{ZnO}$, formada por uma estrutura tridimensional de nanofios de silicone acopladas a nanobastões de $\mathrm{ZnO}$ que permitiu um aumento da eficiência dos dispositivos, tornando a arquitetura promissora para aplicações em células solares sensibilizadas por pontos quânticos. Em 2012, Zhang e colaboradores propuseram a combinação de dois tipos diferentes de $\mathrm{TiO}_{2}$, depositados em camada com o intuito de melhorar o desenvolvimento do substrato, que atua como receptor de elétrons. ${ }^{50}$

Em 2011, Kang e colaboradores descreveram uma comparação entre fotocatodos sensibilizados por corantes e fotocatodos de $\mathrm{NiO}$ sensibilizados por pontos quânticos, mostrando assim a diferença na velocidade de transporte dos buracos, sendo que as células sensibilizadas por pontos quânticos apresentaram uma velocidade de transporte em torno de duas ordens de grandeza maior. ${ }^{118} \mathrm{O}$ transporte muito mais rápido em células de $\mathrm{PQ} / \mathrm{NiO}$, segundo os autores, é presumivelmente devido à forte influência que os estados de superfície têm na determinação da dinâmica do portador de carga. Nos filmes de $\mathrm{TiO}_{2}$ sensibilizados por corantes as armadilhas de superfície limitam o transporte de elétrons. ${ }^{119}$ Assim, atribui-se o transporte mais rápido dos buracos à uma redução da densidade de armadilhas de superfície conformadas pela cobertura da superfície do semicondutor $(\mathrm{NiO})$ pelo ponto quântico (CdS). ${ }^{118}$

Em 2009 Kilina e colaboradores investigaram, por meio de cálculos teóricos, a importância dos ligantes para recobrimento da superfície dos pontos quânticos nas QDSSCs. ${ }^{120}$ A presença desses ligantes afetou fortemente as propriedades eletrônicas dos pontos quânticos e também a interação entre o óxido semicondutor e o sensibilizador. Em 2011, Sykora e colaboradores elucidaram a transferência de elétrons de pontos quânticos $(\mathrm{CdSe})$ revestidos por dois ligantes diferentes: butilamina (BA) e trioctilfosfina (TOPO) adsorvidos em $\mathrm{TiO}_{2}$. Os autores mostraram que nos filmes de $\mathrm{CdSe} / \mathrm{TiO}_{2}$ preparados sem a utilização de ligantes, a eficiência de transferência de elétrons do $\mathrm{TiO}_{2}$ é sensível ao tipo de passivação. A mudança do ligante, de TOPO para BA resulta em (1) uma melhoria na velocidade de transferência de carga, creditada a um melhor acoplamento eletrônico entre o PQ e o filme de $\mathrm{TiO}_{2}$, resultante do comprimento reduzido do ligante passivador, e (2) um aumento da força motriz para a transferência de elétrons resultantes da distorção na estrutura eletrônica do PQ após a adsorção sobre o $\mathrm{TiO}_{2}{ }^{121}$

Estudos recentes têm descrito células solares sensibilizadas por pontos quânticos recobertas com uma camada de $\mathrm{ZnS}$, com o intuito de evitar a recombinação dos pares elétrons-buracos com o eletrólito, levando a desativação da célula. Em 2011, Toyoda e sua equipe propuseram um novo aparato, utilizando o $\mathrm{ZnS}$, que é um semicondutor de ampla banda proibida e atua como uma barreira à recombinação eletrônica para a desativação da célula solar. ${ }^{122}$ A Figura 7 ilustra a arquitetura da célula solar com a presença de ligantes proposta por Toyoda, que consistiu em deposições de $\mathrm{ZnS}$ sobre o ponto quântico CdSe. Essa estrutura permitiu analisar melhor tanto a interface entre o eletrólito/ $/ \mathrm{TiO}_{2}$, quanto a ativação do ponto quântico de CdSe e também entender melhor os mecanismos da reação de transferência eletrônica para assim melhorar a eficiência da célula solar. ${ }^{122}$

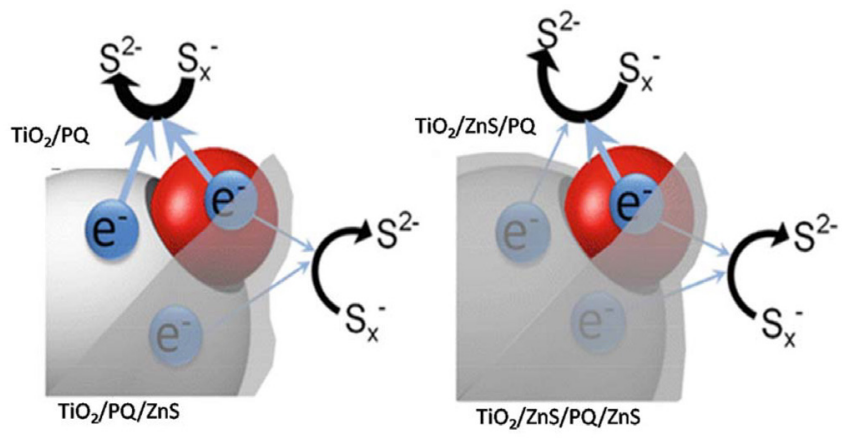

Figura 7. Arquitetura que ilustra a presença de uma camada de ZnS recobrindo os pontos quânticos de CdSe. Adaptado da ref. 122

Analisando a Figura 7 pode-se perceber que quando o ponto quântico é recoberto com o $\mathrm{ZnS}$, a estrutura se comporta como um core/shell. O ZnS recobre a porção exposta ao eletrólito deixando inalterada a interface $\mathrm{TiO}_{2} / \mathrm{CdSe}$ e melhorando a ação do fotoanodo. ${ }^{40,122}$ Utilizando duas camadas de $\mathrm{ZnS}$, o ligante age primeiramente em uma forte interação com o $\mathrm{TiO}_{2}$ e a segunda camada de $\mathrm{ZnS}$ atua no sentido de evitar a recombinação dos elétrons com o eletrólito. A partir de então, a maioria dos trabalhos envolvendo QDSSCs tem usado a deposição de duas camadas de $\mathrm{ZnS}$ sobre o PQ visando evitar recombinações. 


\section{OUTROS ARRANJOS DE CÉLULAS SOLARES ENVOLVENDO PONTOS QUÂNTICOS}

Diversas configurações de células solares contendo pontos quânticos são possíveis. Merecem destaque as células de junção Schottky, células sólidas, células híbridas, as de heterojunção e as de homojunção. A Figura 8 mostra uma representação esquemática de algumas das principais arquiteturas de dispositivos de células solares à base de pontos quânticos.

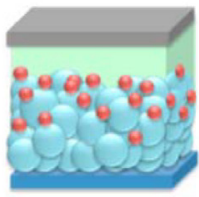

(a)

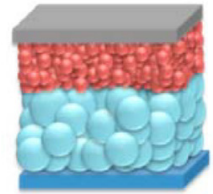

(d)

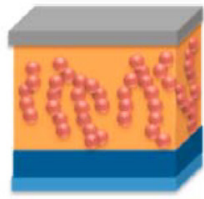

(b)

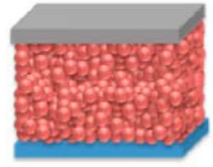

(c)

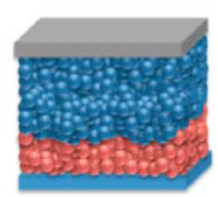

(e)

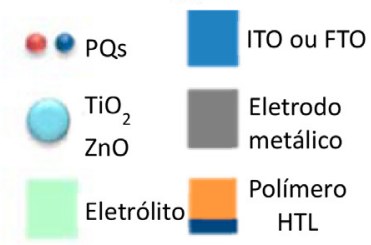

TL
Figura 8. Representação esquemática das arquiteturas de células solares (a) sensibilizada por pontos quânticos, (b) híbrida, (c) de junção Schottky, (d) de heterojunção p-n e (e) de homojunção p-n. Adaptado da ref. 123

\section{Células solares sólidas}

A estabilidade das células solares sensibilizadas por pontos quânticos de junção líquida é limitada pelo uso de um eletrólito líquido, que muitas vezes é responsável por vazamentos nas células e também pela degradação do material absorvedor de luz. Com o intuito de solucionar esses problemas, as células solares de junção líquida estão evoluindo para as células solares sólidas, que consiste na substituição do eletrólito líquido por um material sólido transportador de buracos (HTM, do inglês hole transporting material). ${ }^{40,124}$ Entretanto, uma das maiores limitações da célula solar sólida é a dificuldade dos HTMs penetrarem na matriz do óxido semicondutor.

A primeira célula solar sólida, utilizando pirita, foi demonstrada em 1984 por Tributsch e Ennaoui. ${ }^{124}$ Em 2003, Zeng e colaboradores descreveram uma célula solar sólida, utilizando pontos quânticos de InP obtidos via coloidal, com o objetivo de mostrar os benefícios práticos adquiridos com este dispositivo, bem como uma possível melhoria na quantização e consequentemente na eficiência obtida. ${ }^{125}$

Em 2012, Barceló e sua equipe apresentaram a primeira montagem da célula solar sólida utilizando pontos quânticos de CdSe obtidos pelo método SILAR e como HTM um semicondutor orgânico do tipo $\mathrm{p}$, alcançando valores consideráveis de potencial. ${ }^{126}$ Entretanto, o valor de eficiência obtido ainda se encontra longe do desejado, aproximadamente $0,34 \%$, evidenciando assim a necessidade de mais estudos na configuração deste dispositivo fotovoltaico.

\section{Células solares de junção Schottky}

A célula solar de junção Schottky é um sistema fotovoltaico bem simples, em que pontos quânticos coloidais ficam posicionados entre dois contatos para a posterior formação de elétrons e buracos. Nesse tipo de célula solar, semicondutores do tipo $p$ são sobrepostos em um vidro condutor (ITO) que atua como um contato para que ocorra a extração de cargas. A formação de bandas ocorre devido à transferência de cargas entre o contato metálico e os pontos quânticos, resultando então na barreira Schottky, que favorece a extração de elétrons do dispositivo por meio do contato. ${ }^{40,127}$ Esse aparato experimental apresenta vantagens, como a necessidade de uma fina camada de pontos quânticos da ordem de $100 \mathrm{~nm}$ e também desvantagens como a possível recombinação entre pares e elétrons. ${ }^{40}$

\section{Células solares híbridas - ponto quântico/polímero}

Os primeiros trabalhos sobre células solares híbridas com polímeros e pontos quânticos foi relatado quase ao mesmo tempo que as QDSSC. ${ }^{128}$ Nesta configuração de célula, uma única camada fotoativa é preparada através da mistura de PQs com polímeros conjugados, ou PQs e polímeros são alternadamente dispostos em camadas separadas para construir uma célula de configuração plana ou de bicamadas. ${ }^{129,130}$

Na interface $\mathrm{PQ} /$ polímero fica a separação de cargas e ela é ditada pelos seus níveis de energia. Devido à baixa mobilidade do portador de carga dos polímeros orgânicos semicondutores, a espessura da camada fotoativa fica restrita, limitando a eficiência das células. A mais alta eficiência foi conseguida por Ren e colaboradores e atingiu a marca de $4,1 \%$ com a utilização de pontos quânticos de CdS. ${ }^{130}$ Apesar dessas células híbridas não terem se desenvolvido tão bem quanto outras células de baixo custo, elas possuem grandes possibilidades de atingir um melhor desempenho em sistemas ternários, uso de nanopartículas em redes de aerogéis e manipulação química da superfície da célula. ${ }^{131}$

\section{Células solares de heterojunção}

As células solares de heterojunção $p$ - $n$ baseadas em pontos quânticos só foram desenvolvidos recentemente, em 2009. ${ }^{132}$ Essas células solares geralmente usam a região da heterojunção empobrecida entre um filme de PQ, do tipo $p$, e uma camada de $\mathrm{TiO}_{2}$, do tipo $n$, para separar os portadores de carga fotogerados na camada do PQ. ${ }^{133} \mathrm{Uma}$ célula solar de $\mathrm{ZnO}$ com $\mathrm{PbS}$ e o uso da engenharia de alinhamento de bandas foi a mais eficiente, alcançando $8,55 \%$ de eficiência. ${ }^{134}$ A engenharia de alinhamento de bandas das camadas de PQs foi feita através da utilização de diferentes tratamentos de ligantes. A inserção de uma camada de $\mathrm{PbS}$ com um ligante diferente não só impede o fluxo de elétrons para o anodo, mas também pode reduzir a recombinação de elétrons-buracos na interface.

\section{Células solares de homojunção}

O mais recente desenvolvimento em células solares de pontos quânticos se dá por essas células de homojunção $p-n \cdot{ }^{135-137}$ Com a substituição da camada aceitadora de elétrons, a camada espessa de $\mathrm{TiO}_{2}$, por uma camada de PQ do tipo $n$, a junção pode ser composta unicamente por PQs, do tipo $p$ de um lado, e do tipo $n$ do outro. A justificativa dessa configuração é que os fótons solares podem ser absorvidos por ambos os lados da junção, e os portadores de carga podem ser eficientemente gerados e separados. Com essa arquitetura, uma eficiência de $6,6 \%$ foi alcançada. ${ }^{137}$

\section{CONSIDERAÇÕES FINAIS}

Os pontos quânticos têm se apresentado como uma grande promessa para aplicação em sistemas fotovoltaicos. Características intrínsecas desse material, como por exemplo a relação do tamanho das nanopartículas com a luminescência é o principal responsável pelo destaque dado a esse semicondutor na atualidade.

Nos dias atuais, várias configurações de dispositivos fotovoltaicos utilizando pontos quânticos vêm sendo estudadas. Novos materiais e seus avanços também já são reportados na literatura, bem como o 
aumento da eficiência de conversão desse material que atualmente é de $11,3 \%$.

O emprego dos pontos quânticos obtidos via rota coloidal tem permitido a melhor configuração do sistema fotovoltaico, aliado a melhores resultados. Entretanto, o uso de eletrólito líquido pode gerar vazamento nas células e até mesmo oxidar os materiais absorvedores de luz. Nesse sentido, a célula solar sólida tem surgido como uma alternativa viável e com bons rendimentos de conversão.

Com o aumento do interesse nas energias limpas e renováveis, é muito importante que essas tecnologias continuem a serem desenvolvidas e tornem-se economicamente viáveis em médio prazo, para que, assim, grandes avanços no setor energético mundial possam de fato ocorrer.

\section{AGRADECIMENTOS}

Os autores agradecem à CAPES, ao CNPq, à FINEP e à FAPEMIG pelo apoio recebido.

\section{REFERÊNCIAS}

1. Tolentino, M.; Rocha-Filho, R. C.; Quim. Nova Esc. 1998, 8, 10.

2. Ruhle, S.; Shalom, M.; Zaban, A.; Chem. Phys. Chem. 2010, 11, 2290.

3. Armaroli, N.; Balzani, V.; Angew. Chem., Int. Ed. 2006, 45, 2.

4. Sousa, S. F.; Patrocinio, A. O. T.; Quim. Nova 2014, 37, 886.

5. Silva, F. A.; Viol, L. C. S.; Ferreira, D. L.; Alves, J. L. A.; Schiavon, M. A.; Quim. Nova 2010, 33, 1933.

6. http://www.nrel.gov, acessada em novembro de 2016.

7. Polman, A.; Knigth, M.; Garnett, E. C.; Ehrler, B.; Sinke, W. C.; Science 2016, 352, 307.

8. Carvalho, E. F. A.; Calvete, M. J. F.; Rev. Virtual Quim. 2010, $2,192$.

9. Brown. A. S.; Green, M. A.; Phys. E 2002, 14, 96.

10. Schockley, W.; Queisser, H. J.; J. Appl. Phys. 1961, 32, 510.

11. Dye-Sensitized Solar Cells; Kalyanasundaram, K., ed.; EPFL Press: Lausanne, 2010.

12. http://www.ieee.org.br/wp-content/uploads/2014/05/energia-solar-fotovoltaica-terceira-geracao.pdf, acessada em novembro de 2016.

13. Yan, J.; Saunders, B. R.; RSC Adv. 2014, 4, 432864.

14. Bagher, A. M.; Int. J. Renewable Sustainable Energy 2014, 3, 53.

15. O'Regan, B.; Gratzel, M.; Nature 1991, 353, 737.

16. Quintanilha, R. C.; Rocha, I.; Vichessi, R. B.; Lucht, E.; Naidek, K.; Winnischofer, H.; Vidotti, M.; Quim. Nova 2014, 37, 677.

17. Longo, C.; De Paoli, M-A.; J. Braz. Chem. Soc. 2003, 14, 889.

18. Hagfeld, A.; Boschloo, G.; Sun, L.; Kloo, L.; Pettersson, H.; Chem. Rev. 2010, 110, 6595.

19. Godibo, D. J.; Anshebo, S. T.; Anshebo, T. Y.; J. Braz. Chem. Soc. 2015, $26,92$.

20. Patrocínio, A. O. T.; Iha, N. Y. M.; Quim. Nova 2010, 33, 578.

21. Sonai, G. G.; Melo Jr., M. A.; Nunes, J. H. B.; Megiatto Jr., J. D.; Nogueira, A. F.; Quim. Nova 2015, 38, 1357.

22. Ito, B. I.; Freitas, J. D.; De Paoli, M-A, Nogueira, A. F.; J. Braz. Chem. Soc. 2008, 19, 688.

23. Su'ait, M. S.; Rahman, M. Y. A.; Ahmad, A.; Sol. Energy 2015, 115, 452.

24. Mathew, S.; Yella, A.; Gao, P.; Humphry-Baker, R.; Curchod, B. F. E.; Ashari-Astani, N.; Tavernelli, I.; Rothlisberger, U.; Nazeeruddin, M. K.; Gratzel, M.; Nat. Chem. 2014, 6, 242.

25. Vale, B. R. C.; Vieira, K. O.; Souza, J. C. L.; Ferrari, J. L.; Schiavon, M. A.; Quim. Nova 2015, 38, 22.

26. Martins, M. A.; Trindade, T.; Quim. Nova 2012, 35, 1434.

27. Lan, X.; Masala, S.; Sargent, E. H.; Nature 2014, 13, 233

28. Silva, F. O.; Dissertação de Mestrado, Universidade Federal de São João del-Rei, Brasil, 2010.

29. Nozic, A. J.; Micic, O. I.; Mater. Res. Bull. 1998, 23, 24.
30. Madelung, O.; Schulz, M.; Weiss, H.; Landolt-Bornstein: numerical data and functional relationships in science and technology, new series, group III: crystal and solid state physics, vol. III/17b. Springer: Berlin, 1982

31. Singh, J.; Physics of semiconductors and their heterostructures, McGraw-Hill: New York, 1993.

32. Du, J.; Du, Z.; Hu, J. S.; Pan, Z.; Shen, Q.; Sun, J.; Long, D.; Dong, H.; Sun, L.; Zhong, X.; Wan, L. J.; J. Am. Chem. Soc. 2016, 138, 4201.

33. Duan, J.; Zhang, H.; Tang, Q.; He, B.; Yu, L.; J. Mater. Chem. A 2015 , 3, 17497.

34. Lacroix, L-M.; Delpech, F.; Nayral, C.; Lachaize, S.; Chaudret, B.; Interface Focus 2013, 3, 20120103.

35. Ekimov, A. I.; Onuschenko, A. A.; Soviet Physics - Semiconductors 1982, 16, 1215.

36. Murray, C. B.; Norris, D. J.; Bawendi, M. G.; J. Am. Chem. Soc. 1993, $115,8706$.

37. Rogach, A. L.; Katsikas, L. Kornowski, A.; Su, D.; Eychmuller, A.; Weller, H.; Ber. Bunsenges. Phys. Chem. 1996, 100, 1772.

38. Danck, M.; Jensen, K. F.; Murray, C. B.; Bawendi, M. G.; Chem. Mater. 1996, 8, 173.

39. Zhang, Y.; Clapp, A.; Sensors 2011, 11, 11036.

40. Emim, S.; Singh, S. P.; Han, L.; Saton, H.; Islam, A.; Sol. Energy 2011, 85, 1264.

41. Vogel, R.; Pohl, K.; Weller, H.; Chem. Phys. Lett. 1990, 174, 241.

42. Kouhnavard, M.; Ikeda, S.; Ludin, N. A.; Khairudin, N. B. A.; Ghaffari, B. V.; Mat-Teridi, M. A.; Ibrahim, M. A.; Sopian, K.; Sustainable Energy Rev. 2014, 37, 397.

43. Jun, H. K.; Arof, A. K.; Renewable Sustainable Energy Rev. 2013, 22, 148.

44. Scandola, F.; Bignozzi, C. A.; Quim. Nova 1997, 20, 423.

45. Kamat, P. V.; Acc. Chem. Res. 2012, 45, 1906.

46. Kamat, P. V.; J. Phys. Chem. Lett. 2013, 4, 908.

47. O'Regan, B.; Gratzel, M.; Nature 1991, 353, 737.

48. Giménez, S.; Mora-Seró, I.; Macor, L.; Guijarro, N.; Lana-Villarreal, T.; Gómez, R.; Diguna, L. J.; Shen, Q.; Toyoda, T.; Bisquert, J.; Nanotechnology 2009, 20, 295204.

49. Fan, S.-Q.; Fang, B.; Kim, J. H.; Kim, J.-J.; Yu, J.-S.; Ko, J.; Appl. Phys. Lett. 2010, 96, 063501.

50. Zhang, H.; Cheng, K.; Hou, Y. M.; Fang, Z.; Pan, Z. X.; Wu, W. J.; Hua, J. L.; Zhong, X. H.; Chem. Commun. 2012, 48, 11235.

51. Santra, P. K.; Kamat, P. V.; J. Am. Chem. Soc. 2012, 134, 2508.

52. Hetsch, F.; Xu, X.; Wang, H.; Kershaw, S. V.; Rogach, A. L.; J. Phys. Chem. Lett. 2011, 2, 1879.

53. Li, L.; Yang, X.; Zhang, W.; Zhang, H.; Li, X.; J. Power Sources 2014, 272, 508.

54. Lee, Y. H.; Im, S. Y.; Lee, J. Seok, S. I.; Electrochim. Acta 2011, 56, 2087.

55. Wang, C.; Jiang, Z.; Wei, L.; Chen, Y.; Jiao, J.; Eastman, M.; Liu, H.; Nano Energy 2012, 1, 440.

56. Zhang, S.; Lan, Z.; Wu, J.; Chen, X.; Zhang, C.; J. Alloy. Compd. 2016, 656, 253.

57. Fan, S.; Kim, D.; Kim, J.; Jung, D. W.; Kang, S. O.; Ko, J.; Electrochem. Commun. 2009, 11, 1337.

58. Seol, M.; Kim, H.; Tak, Y.; Yong, K.; Chem. Commun. 2010, 46, 5521.

59. Luo, J.; Karuturi, S. K.; Liu, L.; Su, L. T.; Tok, A. I. Y.; Fan, H. J.; Sci. Rep. 2012, 2, 451.

60. Liu, I.; Chang, C.; Teng, H. Lee, Y.; ACS Appl. Mater. Interfaces 2014, 6, 19378.

61. Hossain, M. A.; Jennings, J. R.; Shen, C.; Pan, J. H.; Koh, Z. Y.; Mathews, N.; Wang, Q.; J. Mater. Chem. 2012, 22, 16235.

62. Chen, X. Q.; Li, Z.; Bai, Y.; Sun, Q.; Wang, L. Z.; Dou, S. X.; Chem. Eur. J. 2015, 21, 1055.

63. Wang, S.; Dong, W.; Fang, X.; Wu, S.; Tao, R.; Deng, Z.; Shao, J.; Hu, L.; Zhu, J.; J. Power Sources 2015, 273, 645. 
64. Tian, J.; Gao, R.; Zhang, Q.; Zhang, S.; Li, Y.; Lan, J.; Qu, X.; Cao, G.; J. Phys. Chem. C 2012, 116, 18655.

65. Seo, H.; Ichida, D.; Uchida, G.; Itagaki, N.; Koga, K.; Shiratani, M.; Jpn. J. Appl. Phys. 2014, 53, 4 .

66. Kim, B.; Son, M.; Kim, S.; Hong, N.; Park, S.; Jeong, M.; Seo, H.; Prabhakar, K.; Kim, H.; Electrochim. Acta 2014, 117, 92.

67. Wang, S.; Dong, W.; Fang, X.; Shu Zhou; Shao, J.; Deng, Z.; Tao, R.; Zhang, Q.; Hu, L.; Zhu, J.; Electrochim. Acta 2015, 154, 47.

68. Gopi, C. V. V. M.; Rao, S. S.; Kim, S.; Punnoose, D.; Kim, H.; J. Power Sources 2015, 275, 547 .

69. Huang, X.; Huang, S.; Zhang, Q.; Gui, X.; Li, D.; Luo, Y.; Shen, Q.; Toyoda, T.; Meng, Q.; Chem. Commun. 2011, 47, 2664.

70. Zhang, Q.; Guo, X.; Huang, X.; Huang, S.; Li, D.; Luo, Y.; Shen, Q.; Toyoda, T.; Meng. Q.; Phys. Chem. Chem. Phys. 2011, 13, 4659.

71. Sudhagar, P.; Gonzalez-Pedro, V.; Mora-Sero, I.; Fabregat-Santiago, F.; Bisquert, J.; Kang, Y. S.; J. Mater. Chem. 2012, 22, 14228.

72. Pan, Z.; Zhang, H.; Chang, K.; Hou, Y.; Hua, J.; Zhong, X.; ACS Nano 2012, 6, 3982.

73. Zhang, Q.; Chen, G.; Yang, Y.; Shen, X.; Zhang, Y.; Li, C. Yu, R.; Luo, Y.; Li, D. Meng, Q.; Phys. Chem. Chem. Phys. 2012, 14, 6479.

74. Cao, Y.; Xiao, Y.; Jung, J.; Um, H.; Jee, S.; Choi, H. M.; Bang, J. H. Lee, J.; ACS Appl. Mater. Interfaces 2013, 5, 479.

75. Zhang, X.; Hung, X.; Yang, Y.; Hen Wang, S.; Gong, Y.; Luo, Y.; Li, D.; Meng, Q.; ACS Appl. Mater. Interfaces 2015, 5, 5954.

76. Yu, X.; Lei, B.; Kuang, D.; Su, C.; Chem. Sci. 2011, 2, 1396.

77. Lee, Y.; Lo, Y.; Adv. Funct. Mater. 2009, 19, 604.

78. Zhu, G.; Pan, L.; Xu, T.; Sun, Z.; ACS Appl. Mater. Interfaces 2011, 3, 3146.

79. Radich, J. G.; Dwyer, R.; Kamat, P. V.; J. Phys. Chem. Lett. 2011, 2, 2453.

80. Wang, J.; Mora-Seró, I,; Pan, Z.; Zhao, K.; Zhang, H.; Feng, Y.; Yang, G.; Zhong, X.; Bisquert, J.; J. Am. Chem. Soc. 2013, 135, 15913.

81. Sung, S. D.; Lim, I.; Kang, P.; Lee, C.; Lee, W. I.; Chem. Commun. 2013, 49, 6054.

82. Tao, L.; Xiong, Y.; Liu, H.; Shen, W.; Nanoscale 2014, 6, 931.

83. Jumabekov, A. N.; Cordes, N.; Siegler, T. D.; Docampo, P.; Ivanova, A.; Fominykh, K.; Medina, D. D.; Peter, L. M.; Bein, T.; ACS Appl. Mater. Interfaces 2016, 8, 4600.

84. Roelofs, K. E.; Herron, S. M.; Bent, S. F.; ACS Nano 2015, 9 , 8321.

85. Jiao, S.; Wang, J.; Shen, Q.; Li, Y.; Zhong, X.; J. Mater. Chem. A 2016 , 4,7214 .

86. Pan, Z. X.; Mora-Sero, I.; Shen, Q.; Zhang, H.; Li, Y.; Zhao, K.; Wang, J.; Zhong, X. H.; Bisquert, J.; J. Am. Chem. Soc. 2014, 136, 9203.

87. Jara, D. H.; Yoon, S. J.; Stamplecoskie, K. G.; Kamat, P. V.; Chem. Mater. 2014, 26, 7221.

88. Lin, C.; Teng, C.; Li, T.; Lee, Y.; Teng, H.; J. Mater. Chem. A 2013, 1, 1155.

89. Chang, J.; Lin, J.; Su, C.; ACS Appl. Mater. Interfaces 2013, 5, 8740

90. Kim, J. Y.; Yang, J.; Yu, J. H.; Baek, W.; Lee, C. H.; Son, H. J. Hyeon, T.; Ko, M. J.; ACS Nano 2015, 9, 11286.

91. Kim, H.; Hwang, I.; Yong, K.; ACS Appl. Mater. Interfaces 2014, 6, 11245 .

92. Choi, Y.; Seol, M.; Kim, W.; Yong, K.; J. Phys. Chem. C 2014, 118 , 5664.

93. Li, Y.; Wei, L.; Wu, C.; Chen, Y.; Liu, H.; Jiao, J.; Mei, L.; J. Mater. Chem. A 2014, 2, 15546.

94. Dao, V.; Choi, Y.; Yong, K.; Laarina, L. L.; Choi, H.; Carbon 2015, 84, 383.

95. Raj, C. J.; Karthick, S. N.; Park, S.; Hemalatha, K. V.; Kim, S.; Prabhakar, K.; Kim, H.; J. Power Sources 2014, 248, 439.

96. Hossain, M. A.; Jennings, J. R.; Koh, Z. Y.; Wang, Q.; ACS Nano 2011, 5,3172 .
97. Ganapathy, V.; Kong, E.; Park, Y.; Jang, H.; Rhee, S.; Nanoscale 2014, 6, 3296.

98. Wanderley, J. B. M.; Borges, F. M. M.; Ribeiro, J. P.; Pimentel, P. M.; Melo, D. M. A.; Cerâmica 2013, 59, 156.

99. Kojima, A.; Teshima, K.; Shirai, Y.; Miyasaka, T.; J. Am. Chem. Soc. 2009, 17, 6050 .

100. Maity, P.; Dana, J.; Ghosh, H. N.; J. Phys. Chem. C, no prelo.

101. Im, J-H.; Lee, G-R.; Lee, J-W.; Park, S-W.; Park, N-G.; Nanoscale 2011, 3, 4088.

102. Kulbak, M.; Gupta, S.; Kedem, N.; Levine, I.; Bendikov, T.; Hodes, G.; Cahen, D.; J. Phys. Chem, Lett. 2016, 7, 167.

103. Guijarro, N, Lana-Villarreal, T ,Mora-Sero, I, Bisquert, J, Gómez, R.; J Phys Chem C 2009, 113, 4208.

104. Lee, H.; Wang, M.; Chen, P.; Gamelin, D. R.; Zakeeruddin, S. M.; Gratzel, M.; Nazeeruddin, M. K.; Nano Lett. 2009, 9, 4221.

105. McDaniel, H.; Fuke, N.; Makarov, N. S.; Pietryga, J. M.; Klimov, V. I.; Nat. Commun. 2013, 4, 2887.

106. Zaban, A.; Micic, O. I.; Gregg, B. A. Nozik, A. J.; Langmuir 1998, 14, 3153.

107. Kuo, K.; Liu, D.; Chen, S.; Lin, C.; J. Mater. Chem. 2009, 19, 6780.

108. Shi, A.; Sun, J.; Zeng, Q.; Shao, C.; Sun, Z.; Li, H.; Kong, X.; Zhao, J.; J. Lumin. 2011, 131, 1536.

109. Shuney-Haj-Chia, L.; Basnar, B.; Willner, I.; Angew. Chem., Int. Ed. 2005, 44, 78.

110. Farrow, B.; Kamat, P. V.; J. Am. Chem. Soc. 2009, 131, 11124.

111. Lee, W.; Kang, S. H.; Min, S. K.; Sung, Y. -E.; Han, S. -H.; Electrochem. Commun. 2008, 10, 1579.

112. Chen, J.; Wu, J.; Lei, W.; Song, J. L.; Deng, W. Q.; Sun, X. W.; Appl. Surf. Sci. 2010, 256, 7438.

113. Lightcap, I. V.; Kamat, P. V.; J. Am. Chem. Soc. 2012, 134, 7109.

114. Nogueira, A. F.; Tese de Doutorado, Universidade Estadual de Campinas, Brasil, 2001.

115. Barceló, I.; Lana-Vilarreal, T.; Gomez, R.; J. Photochem. Photobiol., A 2011, 220, 47.

116. Sudhagar, P.; Song, T.; Lee, D. H.; Mora-Seró, I.; Bisquert, J.; Laudenslager, M.; Sigmund, W. M.; Park, W. I.; Paik, U.; Kang, Y. S.; J. Phys. Chem. 2011, 2, 1984.

117. Kang, S. H.; Zhu, K.; Neale, N. R.; Frank, A. J.; Chem. Commun. 2011, $47,10419$.

118. Zhu, K.; Kopidakis, N.; Neale, N. R.; van de Lagemaat, J.; Frank, A. J.; J. Phys. Chem. B 2006, 110, 25174.

119. Kilina, S.; Ivanov, S.; Tretiak, S.; J. Am. Chem. Soc. 2009, 131, 7717.

120. Szymanski, P.; Fuke, N.; Koposov, A. Y.; Manner, V. W.; Hoch, L. B.; Sykora, M.; Chem. Commun. 2011, 47, 6437.

121. Guijarro, N.; Campina, J. M.; Shen, Q.; Toyoda, T.; Lana-Vilarreal, T.; Gomez, R.; Phys. Chem. Chem. Phys. 2011, 13, 12024.

122. Kim, M. R.; Ma, D.; J. Phys. Chem. Lett. 2015, 6, 85.

123. Dittrich, T.; Belaidi, A.; Ennauoui, A.; Sol. Energy Mater. Sol. Cells 2011, 95, 1527.

124. Zeng, T.; Gladwin, E.; Claus, R. O.; Mater. Res. Soc. Symp. Proc. 2003 , $764,171$.

125. Farrow, B.; Kamat, P. V.; J. Am. Chem. Soc. 2009, 131, 11124

126. Wu, J.; Wang, Z. M.; Quantum Dot Solar Cells, Springer: New York, vol. 15, 2014.

127. Greenham, N. C.; Peng, X. G.; Alivisatos, A. P.; Phys. Rev. B 1996, 54 , 17628.

128. Leventis, H. C.; King, S. P.; Sudlow, A.; Hill, M. S.; Molloy, K. C.; Haque, S. A.; Nano Lett. 2010, 10, 1253.

129. Ren, S. Q.; Chang, L. Y.; Lim, S. K.; Zhao, J.; Smith, M.; Zhao, N.; Bulovic, V.; Bawendi, M.; Gradecak, S.; Nano Lett. 2011, 11, 3998.

130. Freitas, J. N.; Gonçalves, A. S.; Nogueira, A. F.; Nanoscale 2014, 6, 6371. 
131. Leschkies, K. S.; Beatty, T. J.; Kang, M. S.; Norris, D. J.; Aydil, E. S.; ACS Nano 2009, 3, 3638.

132. Pattantyus-Abraham, A. G.; Kramer, I. J.; Barkhouse, A. R.; Wang, X. H.; Konstantatos, G.; Debnath, R.; Levina, L.; Raabe, I.; Nazeeruddin, M. K.; Gratzel, M.; Sargent, E. H.; ACS Nano 2010, 4, 3374.

133. Chuang, C. H.; Brown, P. R.; Bulovic, V.; Bawendi, M. G.; Nat. Mater. 2014, 13, 796 .

134. Tang, J.; Liu, H.; Zhitomirsky, D.; Hoogland, S.; Wang, X. H.; Furukawa, M.; Levina, L.; Sargent, E. H.; Nano Lett. 2012, 12, 4889.
135. Liu, H.; Zhitomirsky, D.; Hoogland, S.; Tang, J.; Kramer, I. J.; Ning, Z. J.; Sargent, E. H.; Appl. Phys. Lett. 2012, 101, 15112.

136. Adinolfi, V.; Ning, Z.; Xu, J.; Masala, S.; Zhitomirsky, D.; Thon, S. M.; Sargent, E. H.; Appl. Phys. Lett. 2013, 103, 011106.

137. Ning, Z. J.; Ren, Y.; Hoogland, S.; Voznyy, O.; Levina, L.; Stadler, P.; Lan, X. Z.; Zhitomirsky, D.; Sargent, E. H.; Adv. Mater. 2012, 24, 6295. 